\title{
ATTITUDINAL FACTORS AFFECTING WIKI GROUP COLLABORATION FOR ENGLISH WRITING
}

\author{
ChwenJenChen[cichen@fcs.unimas.my],Kee Man Chuab[kmchuah@fcs.unimas.my],Jimmy Tho \\ [masitan2001@yahoo.com.hk], Chee SiongTeh [csteh@fcs.unimas.my], Universiti Malaysia Sarawak, \\ Malaysia [www.unimas.my]
}

\begin{abstract}
Wikis, being one of the popular Web 2.0 tools, have impacted students' engagement and performance particularly in the aspects of second and foreign language learning. While an increasing number of studies have focused on the effectiveness of wiki in improving students' writing skills, this study was conducted to examine the attitudinal factors that influence English as a Second Language (ESL) students' group collaboration in using wikis for a writing task that was divided into three phases: pre-writing, individual-construction, joint-constructions. Data collected from these students after completing this task was analyzed based on three attitudinal aspects: motivation, perceived usefulness, and perceived ease of use. The findings reveal high mean scores for all aspects. Further multiple regression analysis reveals that motivation is the most important factor associated with group collaboration, indicating the need to boost students' motivation to encourage effective collaboration in completing wiki writing tasks.
\end{abstract}

Keywords: Wiki, Attitudinal factors, Collaborative learning, Pedagogical issues, Language learning

\section{Introduction}

The rapid advancement of social technologies has brought a great impact to educational learning environments. Wikis, which are collections of interlinked interactive web pages, emerge as a promising learning technology that allows an individual or a group of users to contribute and share information on these pages. This social computing technology was created by Ward Cunningham in 1994 and has progressively evolved to extend the wiki paradigm for learning and teaching purposes (Buffa \& Gandon, 2006; Denoyer \& Gallinari, 2007; Laru, Näykki \& Järvelä, 2012; Wang \& Turner, 2004; Weiss, Urso \& Molli, 2007; Schaffert, 2006). Although the tool has been in existence for quite some time, its use in various contexts continued to be examined.

Over the past decade, wikis have been widely adopted for facilitating language learning. Numerous studies on the use of wikis for such purposes were reported. Wang, Lu, Yang, Hu, Chiou, Chiang et al. (2005) explored the use of wikis for freshman level English as a second language (ESL) course and report that wikis to be beneficial to learning. Brandl (2005) introduces the implementation of wikis in Moodle for language learning purposes. Ang, Zaphiris and Wilson (2005), on the other hand, used wiki technologies to facilitate new literacy practice through collaborative narrative construction in game communities. Lund (2008) used wikis as a collective approach to language production in an English as a Foreign Language (EFL) classroom and Lee (2010) used wikis to improve students' grammatical knowledge in Spanish. Besides that, Kesler (2009) reports on the use of wikis to improve language skills among pre-service non-native speaker English teachers in a Mexican university while Li (2012) reports on the use of wiki for language classes in many parts of the world such as Europe, America, Australia, and Asia. More recently, Wang (2014a) used wikis among Taiwanese students for English business writing 
purposes, Chao and Lo (2011) used wikis for an English composition course among university students and, Sun and Qiu (2014) used wikis for English business writing among students at a university in China.

\section{Wiki as a collaborative learning tool}

Wikis are acknowledged as an excellent collaborative learning tool in an online environment by numerous researchers and educational practitioners, such as Augar, Raitman and Zhou (2004), Engstrom and Jewet (2005), Lund (2008), Parker and Chao (2007), and Schwartz, Clark, Cossarin and Rudolph (2004). In general, users may create and edit the content of wikis collaboratively. Wikis keep record of all changes and this allows users to revert to any previous states, giving ample opportunities for users to reflect on the previous versions and do necessary improvements. Besides that, the sharing feature of wikis turns wikis into a powerful source of information and the co-edit feature of this technology engages learners in constructing their own knowledge when working on wikis collaboratively.

The nature of affordances provided by the wiki platform is in line with a number of prominent learning theories (Hsu, Ching \& Grabowski, 2014). Specifically, allowing learners to individually construct and co-construct wiki content by building on each other's work supports the theory of distributed cognition by Hutchins (2000) that posits knowledge lies not only within cognitive processes that take place inside an individual but must also consider the individual's social and physical environment. Affording a socially rich environment to explore and exchange ideas with other learners or communities in the wiki platform is consistent with Vygotsky's socio-cultural theory (Vygotsky, 1978) that stresses the role of social interaction in the development of cognition. Ang et al. (2005), Parker and Chao (2007) and Zorko (2009) are among others who highlight the sturdy relationship between principles of social constructivism with wiki affordances. This enables learners to explicitly construct and co-construct their knowledge as well as reflections of their knowledge.

Studies have also revealed positive effects of using wikis for collaborative language learning. Lund (2008) reports the use of wikis in an EFL class benefits collective knowledge advancement and language development. A qualitative study by Zorko (2009) among sociology students who used wikis for ESL course reveals that wikis promote collaborative behaviour such as learning from each other and communicating with the teacher. Another study by Kessler, Bikowski and Boggs (2012) shows that Fulbright scholars who used a Web-based word processing tool to collaboratively plan and report on a research project gave more emphasis on meaning than form as well as demonstrated more accurate grammar use. Woo, Chu and Li (2013) reveals how peer feedback and revision can be optimized through the use of wikis and ultimately improve second language learner's ability in writing. Wang (2014b) also notes similar findings in which wikis promote students' interest and competencies in business writing and enhance their collaboration skills and Chao and Lo (2011) reports high EFL students' satisfaction towards the use of wikibased collaborative writing environment.

Li (2012) who reviewed 21 empirical studies on the use of wikis in second or foreign language classes that were published from 2008 to 2011 have found that these studies predominantly related to the use of wikis for collaborative writing. Li (2012) have also identified four major research strands explored in these studies which are collaborative writing process, writing product, perceptions of wiki-based collaborative writing, and effects of tasks. All these studies shed light on the affordances of wikis for collaborative learning. Despite its affordances, Hughes and Narayan (2009) note that the technical aspects of wikis are one of the factors that hinders learners from fully gaining benefits from the wiki experience. Kawahata and Chung (2013), however, accentuate the importance of investigating the impact of wiki usage on students' 
engagement, motivation, and attitudes. Their study has shown how the implementation of wikis has positively influenced primary school students' attitudes towards peer editing and writing as a whole.

\section{Motivation of the study}

As emphasized by Lai and Morrison (2013), to ensure the effective use of technologies in language learning, learners' willingness to engage in such activities (Holec, 2009), which is an attitudinal factor, is as crucial as their abilities to use technologies in socio-cultural and pedagogical appropriate manners (Healey, Hanson-Smith, Hubbard, Ioannou-Georgious, Kessler \& Ware, 2011; Levy, 2009). Previous studies on attitudinal factors mainly focus on students' perceptions of collaborative behaviours, benefits and challenges of using wikis for learning, and collaborative writing (Li, 2012). Little is known, however, on attitudinal factors that could influence group collaboration in accomplishing a wiki task. Knowing such factors would be useful to inform instructors on the aspects that should be taken into consideration to enhance such wiki group collaboration and ultimately, to increase the likelihood of success from wikibased collaborative language learning environments. Understanding pre-exiting beliefs and attitudes (Davis, 1989) is a productive approach to gain insight on ways to foster effective group collaboration (Greener, 2009). Thus, the aim of this study is to examine whether attitudinal factors such as students' motivation in using wikis, their perception towards the technical affordances of the wiki tool, their perceived usefulness of the tool as well as their perceived ease of use of it may affect such collaboration.

\section{Research questions}

This study focuses on the following research questions:

- RQ1: How do students' perceive their group collaboration through wikis, their motivation in using wikis, the usefulness as well as the ease of use of the wiki platform?

- RQ2: Are there any associations between group collaboration and each of the three examined attitudinal aspects, namely motivation, perceived usefulness, and perceived ease of use?

\section{Methods}

This study involved a total of 45 first year undergraduate students from five different faculties of a public university. These students, at the time of this study were undertaking a remedial English course at the Centre for Language Studies to improve their writing skills. There were 7 males and 38 females and all of them had given their consent to participate in this study. These students were requested to perform a wiki task and thereafter to respond to a questionnaire. Both the wiki task and the questionnaire are elaborated as follows.

\section{The wiki task}

During the class hours of the remedial English course, the writing lessons focused mainly on the structure and language features of the discussion genre. To assist them in the production of the essay, wiki tasks were used via the university's learning management system. The tasks consisted of three phases: pre-writing, individual-construction, joint-construction. In the first phase, students were told to form groups of five and each group was given a topic. Based on the given topic, they had to gather necessary information and outline key points in the form of mind mapping. In the second phase, they were required to produce an essay draft in their individual wiki space based on the points gathered in the pre-writing phase. Once the individual draft was presented, the members within the group were told to edit each other's draft. The purpose of this 
phase is to let the students try the wiki tool and familiarize themselves with its features so as to reduce the technical issues of using the tool while at the same time learning the structure of the discussion genre. In the third stage, each group was given a new topic and was required to jointly construct the essay directly on the wiki. They were required to collaboratively edit the essay and produce a finalized version to be presented to the other groups. They were given one week to do so. After that, the instructor gave feedback to each groups' essay for further improvement through face-to-face instructions in class.

\section{Instrument}

The questionnaire used in this study consisted of four main sections. The first two sections on 'Group Collaboration' and 'Motivation' contained items that were adapted from the study by Li, Chu, Ki and Woo (2010). Li et al. (2010) have investigated students and teachers' perception toward collaborative writing with wiki in a Chinese writing class from the aspects of motivation, wiki affordances, and team collaboration. The items for Based on the technology acceptance model suggested by Fred Davis in 1989, perceived usefulness and perceived ease of use of systems characteristics play significant role in predicting system success (Legris, Ingham \& Collerette, 2003). Thus, this instrument includes another two sections on 'Perceived Usefulness' and 'Perceived Ease of Use' which contained items adapted from the Technology Acceptance Model instrument by Davis (1989). Students had to indicate agreement with each item on a 5point Likert scale (1: Strongly Disagree, 5: Strongly Agree). Overall, the questionnaire yielded Cronbach's $\alpha$ reliability coefficient of 0.9 , which was over the minimum 0.6 generally recommended for internal reliability in psychology (Aron, Aron \& Coups, 2006).

Besides the data obtained through questionnaire, the students" "virtual behaviours" in completing the wiki tasks collaboratively were also analysed. The behaviours were recorded via the log files of each wiki, in which all their editing activities are recorded. The log files contained the time spent in completing the task, the number of editing done by each group member, and also the parts changed by the group member. Through this, the study collected the time spent in editing by the individual group member (in minutes) and the number of editing that they have done and correlate with the three factors, motivation, perceived usefulness and perceived ease of use using Pearson's Correlations. This method is used to uncover the general relationships between the construct.

\section{Results and discussion}

Table 1 summarizes the results for all the analysed aspects. These results provide some insights into the first research question.

RQ1: How do students' perceive their group collaboration through wikis, their motivation in using wikis, the usefulness as well as the ease of use of the wiki platform? 
Table 1: Mean score for items and average mean score for all aspects

\begin{tabular}{|c|c|c|}
\hline Aspect & $\begin{array}{l}\text { Mean } \\
\text { score }\end{array}$ & $\begin{array}{c}\text { Average } \\
\text { mean } \\
\text { score }\end{array}$ \\
\hline Group Collaboration & & 3.56 \\
\hline $\begin{array}{l}\text { 1. I learn a lot from my wiki group members, which enriches my } \\
\text { writing content. }\end{array}$ & 3.47 & \\
\hline 2. The contribution of every wiki member is important. & 3.58 & \\
\hline $\begin{array}{l}\text { 3. Interaction among wiki group members improves my writing } \\
\text { ability compared with the only interaction with my instructor. }\end{array}$ & 3.62 & \\
\hline $\begin{array}{l}\text { 4. Overall, the conflict among my wiki group members brings more } \\
\text { benefits than disadvantages. }\end{array}$ & 3.60 & \\
\hline $\begin{array}{l}\text { 5. A good collaboration among wiki group members helps to } \\
\text { produce a better wiki write up. }\end{array}$ & 3.56 & \\
\hline $\begin{array}{l}\text { 6. As compared to the traditional writing, interaction among group } \\
\text { members in wiki improves my writing ability. }\end{array}$ & 3.53 & \\
\hline Motivation & & 3.36 \\
\hline 7. I like writing collaboratively on wiki. & 3.53 & \\
\hline $\begin{array}{l}\text { 8. As compared to writing with pen and paper I prefer writing on } \\
\text { wiki. }\end{array}$ & $\begin{array}{l}3.33 \\
3.49\end{array}$ & \\
\hline 9. Wiki improves my writing interest. & 3.13 & \\
\hline 10. I participate in writing more because of wiki. & 3.36 & \\
\hline $\begin{array}{l}\text { 11. I stay on writing more because of using wiki. } \\
\text { 12. I hope to continue using wiki next semester. }\end{array}$ & 3.40 & \\
\hline Perceived Technical Affordances & & 3.53 \\
\hline 13. Writing on wiki brings more advantages than disadvantages. & 3.42 & \\
\hline $\begin{array}{l}\text { 14. The technology characteristics of wiki help to improve our write- } \\
\text { up. } \\
\text { 15. When writing on wiki, it is easy for us to view and edit our } \\
\text { compositions. }\end{array}$ & $\begin{array}{l}3.67 \\
3.49\end{array}$ & \\
\hline Perceived Usefulness & & 3.64 \\
\hline 16. Using wiki would enable me to accomplish tasks more quickly. & 3.87 & \\
\hline 17. Using wiki in my writing would increase my productivity. & 3.58 & \\
\hline 18. Using wiki would make it easier to do my writing & 3.53 & \\
\hline 19. Using wiki would improve my writing performance. & 3.58 & \\
\hline 20. Using wiki would enhance my effectiveness on writing. & 3.67 & \\
\hline 21. 1 find wiki useful in my writing. & 3.60 & \\
\hline Perceived Ease of Use & & 3.60 \\
\hline 22. My interaction with wiki is clear and understandable. & 3.64 & \\
\hline 23. I find wiki flexible to interact with. & 3.49 & \\
\hline 24. Learning to operate wiki is easy for me. & 3.67 & \\
\hline 25. I find it easy to get wiki to do what I want to do. & 3.44 & \\
\hline 26. It is be easy for me to become skilful at using wiki. & 3.76 & \\
\hline
\end{tabular}

\section{Group collaboration}

Referring to Table 1, the average mean score on how students' perceived their group collaboration through wikis is 3.56. This result shows students' positive perception towards such collaboration and this is in line with the view made by numerous researchers on the potential benefits of wikis that allow students to socially interact and collaborate (Augar et al., 2004; Choy \& Ng, 2007; Schwartz et al., 2004; Wheeler, Yeomans \& Wheeier, 2008).

Generally, the results for the first two items (3.47 and 3.58) show that students agreed that they learned a lot from their wiki group members and acknowledged the importance of their peers' contributions. The respondents to a qualitative study on the use of collaborative wikis for an English undergraduate course by Zorko (2009) also found wikis to be extremely convenient for them to compare their work with their peers' work and this affords learning from each other. 
This result is also in line with Chao and Lo (2011) that reports students' appreciation towards the mutual assistance in linguistic problems during peer editing.

The results for item 3 (3.62), item 4 (3.60), item 5 (3.56), and item 6 (3.53), in general, show that students agreed that the group interaction via wikis helped to improve their writing ability and increased the quality of their write-ups. As pointed out by Sotillo (2002), collaborative writing increases complexity in writing. Storch (2005) and Lee (2010) further assert that such collaboration increases grammatical accuracy and the overall quality of writing. Mak and Coniam (2008) analyze the use of wikis as an online collaborative writing tool for a group of secondary school students. In their project, students were required to produce a brochure about their schools through a series of collaborative drafts and results showed that they were able to increase the quantity as well as quality (expanding, reorganizing, and correcting) of their write-ups. Such finding is once again consistent with the findings from these few items.

\section{Motivation}

As shown in Table 1, the average mean score on students' motivation in using wikis is 3.36 . This result shows that students are generally motivated to use wiki for the collaborative writing task. Many studies such as Chao and Lo (2011), Kessler (2009), Lee (2010), Li, Chu, Ki and Woo (2012), Raitman, Augar and Zhao (2005) and Zorko (2009) also report wikis as interesting and able to motivate learning.

The self-determination theory may help to explain the motivational effect of wikis (Alm, 2006). The theory posits that all humans share the psychological needs of relatedness, competence, and autonomy to develop a sense of self. In terms of relatedness, the interaction among group members and possibly between groups creates the feeling of connectedness to others as well as forms the sense of belongingness. In this study, the carefully designed wiki task which is appropriate to the students' proficiency level may help to support a feeling of competence in them. Students are motivated when they believe they are able to succeed at a given task (Brophy, 2013). As highlighted by Lee (2010), the choice of wiki task affects the level of engagement in collaborative writing. Similarly, in the study by Lund and Smørdal (2006), freedom to choose a specific theme of Hispanic culture motivates students to be more involved in the writing process.

The results for item 7 (3.53), item 8 (3.33) and item 9 (3.49) show students' high interest in using wikis for collaborative writing and their preference in writing on wikis than with pen and paper. This is in accordance to de Paiva Franco's (2008) study on the use of collaborative wikis among Brazilian EFL students and Lee's (2010) study which involved 35 native speakers of English taking elementary Spanish classes where majority of their research participants preferred to use wikis for collaborative writing purposes. Kuswara and Richards (2011) also report stronger preference towards using wikis than doing things manually for collaborative learning. Wikis also seem to afford the third psychological needs of the self-determination theory which is autonomous learning as the results for item 10 (3.13), item 11 (3.36), and item 12 (3.40) show their persistent participation in current writing task as well as awaiting for near future opportunities for similar participation. According to Raitman et al. (2005), wikis which are fully editable empower users with a sense of ownership and authority which are essential in autonomous learning.

\section{Perceived usefulness}

As recognized in Davis's Technology Acceptance Model (1989), negative perceptions of usefulness sometimes set up barriers to achieve effective online group collaboration (Greener, 2009). Referring to Table 1, the average mean score on how students' perceived the usefulness of 
wikis is 3.64. This result shows students' positive perception towards the usefulness of wikis in improving the effectiveness and efficiency of their wiki task.

The results for item 13 (3.87), item 14 (3.58) and item 15 (3.58) depict students' agreement on the efficiency of wikis as wikis help to speed up task accomplishment, reduces effort in writing as well as increase their writing productivity. The availability and easily accessible wikis at anytime and anywhere (Nicol et al., 2005), the empowerment given for students to construct, update, and remove wiki contents (Ravid, Kalman \& Rafaeli, 2008; Thorne \& Payne, 2005) and the provision of a single platform to store compilation of ideas as well as to exchange ideas conveniently possibly explain such efficiency. In addition, results for item 16 (3.58), item 17 (3.67) and item 18 (3.60) indicate students' agreement on the usefulness of wikis in improving their writing. Ma and Yuen (2008) who studied on student journalists learning news writing report that wikis effectively facilitate learners' writing processes; particularly their revision behaviour and this eventually improve their writing performance. In addition, the study by Li et al. (2012) reveals that with wikis, students are more motivated to look for additional information on the web as they are already online and this encourages them to learn new vocabulary and language forms which contribute to improved writing.

\section{Perceived ease of use}

As for the perceived ease of use aspect, the average mean score is 3.60. Generally, results for item 19 (3.64) and item 20 (3.49) indicate that students agreed on having comprehensible and flexible interaction with wikis. Reasons that may possibly explain such a positive perception include the asynchronous nature of wikis that enables students to contribute at their convenience (Bower, 2007), the ability of wikis to easily store various types of digital information (Nicol, Littlejohn \& Grierson, 2005) that meets the net generation's learning expectations and preferences (Baird \& Fisher, 2005), and the visibility of work among group members facilitates sharing of information, resources and ideas (Bower, 2007; Zorko, 2009).

Results for item 21 (3.67), item 22 (3.44), and item 23 (3.76) show that students perceived wikis as easy to become proficient at. One reason for this could be the instructor's inclusion of indirect training in this study, in which students were told to use the wiki tool for individual construction of the writing task before proceeding to join-construction stage with their group members. A review of existing studies shows that there are some inconsistencies in the findings on this aspect. Studies such as Raitman et al. (2005), Bower (2007), Choy and $\mathrm{Ng}$ (2007), and Hughes and Narayan (2009) report users' difficulties in using wikis while Neumann and Hood (2009) report mixed perception. On the other hand, studies such as Zorko (2009), Su and Beaumont (2010), and Kuswara and Richards (2011) describe wikis as robust and user friendly. The continuous advancement made to this technology and the familiarity of the net generation students to various social networking interfaces may help to explain the shift of perception from negative to positive over time.

\section{Predictors}

The multiple regression analysis was conducted to understand whether group collaboration can be predicted based on motivation, perceived usefulness, and perceived ease of use. Table 2, 3 and 4 summarize the results that help to answer the second research question.

RQ2: Are there any associations between group collaboration and each of the three examined attitudinal aspects, namely motivation, perceived usefulness, and perceived ease of use? 
Table 2: Model Summary

\begin{tabular}{ccccc}
\hline Model & $\mathrm{R}$ & $\mathrm{R}$ Square & Adjusted R Square Std. Error of the Estimate \\
\hline 1 & $.906^{\mathrm{a}}$ & .820 & .807 & .3486 \\
\hline
\end{tabular}

a. Predictors: (Constant), Motivation, Perceived Usefulness, Perceived Ease of Use

A value of 0.906 as shown in Table 2 indicates an excellent level of prediction. About $82 \%$ of the variance of group collaboration can be accounted for by the linear combination of motivation, perceived usefulness and perceived ease of use.

Table 3: ANOVA $^{\mathrm{a}}$

\begin{tabular}{llccccc}
\hline Model & & Sum of Squares & $\mathrm{df}$ & Mean Square & $F$ & Sig. \\
\hline \multirow{3}{*}{1} & Regression & 22.764 & 3 & 7.588 & 62.453 & $.000^{\mathrm{b}}$ \\
\cline { 2 - 7 } & Residual & 4.982 & 41 & .122 & & \\
\cline { 2 - 7 } & Total & 27.746 & 44 & & & \\
\hline
\end{tabular}

a. Dependent Variable: Group Collaboration

b. Predictors: (Constant), Motivation, Perceived Usefulness, Perceived Ease of Use

The F-ratio shown in Table 4 indicates that the independent variables significantly predict the dependent variable, $\mathrm{F}(3,41)=62.453$, $\mathrm{p}<.001$ (i.e., the regression model is a good fit of the data).

Table 4: Coefficients

\begin{tabular}{|c|c|c|c|c|c|}
\hline \multirow[t]{2}{*}{ Model } & \multicolumn{2}{|c|}{ Unstandardized Coefficients } & \multirow{2}{*}{$\begin{array}{c}\begin{array}{c}\text { Standardized } \\
\text { Coefficients }\end{array} \\
\text { Beta } \\
\end{array}$} & \multirow[t]{2}{*}{$\mathrm{t}$} & \multirow[t]{2}{*}{ Sig. } \\
\hline & B & Std. Error & & & \\
\hline (Constant) & -.024 & .270 & & -.088 & .931 \\
\hline Motivation & .475 & .086 & .482 & 5.532 & .000 \\
\hline Perceived Usefulness & .418 & 170 & .397 & 2.462 & .018 \\
\hline Perceived Ease of Use & .131 & .154 & .129 & 0.849 & .401 \\
\hline
\end{tabular}

Referring to Table 4, the general form of the equation to predict group collaboration from motivation, perceived usefulness and perceived ease of use is as follows:

Predicted Group Collaboration $=-0.024+(0.475 \times$ motivation $)+(0.418 \times$ perceived usefulness $)+(0.131 \times$ perceived ease of use $)$

This analysis reveals that motivation is the most important factor associated with group collaboration. This is followed by their perceived usefulness of wikis. Students' perceived ease of use is the least important factor in explaining group collaboration.

\section{Correlation between attitudinal factors and behavioural data on collaboration}

To supplement the findings obtained from the questionnaire, the data on attitudinal factors were then correlated with behavioural data of the students' collaboration in completing the wiki-based writing tasks. It was hypothesized that the attitudinal factors should have positive relationships with the actual collaboration, therefore, making them spend longer time in contributing as well as editing the essay more frequently.

Table 5: Correlation between the time spent on wiki task and attitudinal factors

\begin{tabular}{|c|c|c|c|c|}
\hline & & Motivation & $\begin{array}{l}\text { Perceived } \\
\text { Usefulness }\end{array}$ & $\begin{array}{c}\text { Perceived } \\
\text { Ease of Use }\end{array}$ \\
\hline \multirow{3}{*}{$\begin{array}{c}\text { Time Spent for } \\
\text { Wiki Task }\end{array}$} & Pearson Correlation & $.649^{* *}$ & $.593^{* *}$ & -.139 \\
\hline & Sig. (2-tailed) & .000 & .000 & .362 \\
\hline & $\mathrm{N}$ & 45 & 45 & 45 \\
\hline
\end{tabular}

Correlation is significant at the 0.01 level (2-tailed). 
The average time spent by each member of the group in completing the wiki task was approximately 15 minutes and everyone participated in the wiki production. The longest time spent by an individual within the group was 36 minutes while the shortest time was 5 minutes. Table 5 shows the output from Pearson's Correlation coefficients between the time spent on wiki task and attitudinal factors. As indicated, there is a significant and positive relationship between time spent on wiki task and motivation $(\mathrm{r}=0.649, \mathrm{p}<0.01)$ and perceived usefulness $(\mathrm{r}=0.593$, $\mathrm{p}<0.01)$. However, it has no significant relationship with perceived ease of use.

Table 6: Correlation between wiki editing frequency and attitudinal factors

\begin{tabular}{|c|c|c|c|c|}
\hline & & Motivation & $\begin{array}{l}\text { Perceived } \\
\text { Usefulness }\end{array}$ & $\begin{array}{c}\text { Perceived } \\
\text { Ease of Use }\end{array}$ \\
\hline \multirow{3}{*}{$\begin{array}{l}\text { Wiki Editing } \\
\text { Frequency }\end{array}$} & Pearson Correlation & $.729^{\star *}$ & .043 & .192 \\
\hline & Sig. (2-tailed) & .001 & .778 & .206 \\
\hline & $\mathrm{N}$ & 45 & 45 & 45 \\
\hline
\end{tabular}

Correlation is significant at the 0.01 level (2-tailed).

As for editing frequency, the average number recorded from the data was 5 times with the lowest being only one and highest 10 times. In general, students actually edited the essay that they produced rather frequently, which they could not have done in usual classroom writing activity. As indicated in Table 6 , only motivation has a significant and strong relationship with wiki editing frequency $(\mathrm{r}=0.729, \mathrm{p}<0.01)$. It seems to suggest that students with higher motivation tend to collaborate more by editing on each other's essays.

All in all, the behavioural data supports the findings from the questionnaire data reported earlier. The key attitudinal factor in prompting the students to work collaboratively on the wikis is motivation. Perceived usefulness also contributes to the time spent in completing the wiki task, perhaps due to the sense of purpose it gives rather than the writing tasks (either individual or collaborative) done through conventional face-to-face classroom instructions. The editing features in wiki and also the revision logs actually assisted the students to contribute more while working in groups.

\section{Implications}

The findings provide some interesting pedagogical challenges for instructors who use wikis for collaborative writing purposes. The following discussion presents a series of reflections to guide these instructors to enhance collaboration among wiki group members.

Reflection 1: Students' motivation is the most significant predictor for group collaboration. Thus, instructors need to consider factors that affect students' motivation to encourage effective collaboration. In line with the self-determination theory (Alm, 2006), students are motivated when they are given wiki tasks that fit to their level of competence (Brophy, 2013). The design of learning tasks (Choy \& Ng, 2007) that require negotiated meaning (Bower et al., 2006) also encourages participation. As reiterated by Cole (2009), it is insufficient to simply add wikis into a course with a traditionally designed content but rather the course content needs to be explicitly redesigned around wiki use to boost participation. Brophy (2013) also asserts that students are motivated when they understand and appreciate the outcome of the task. Cole (2009) also highlights the need to include some form of assessments on contribution to wikis to promote students' participation. Some forms of support such as appropriate metacognitive and scaffolding strategies are also useful in engaging learners in technology-enhanced language learning environments (Chao \& Lo, 2011; Lee, 2010; Zenotz, 2012). Instructors may also need to decide on the appropriate level of visibility for wikis produced, either public, inter or intra groups, as 
students tend to put more effort for wiki contents that are of visible by many parties (Zorko, 2009).

Reflection 2. As perceived usefulness of wikis is an important aspect that predicts group collaboration, it is thus indispensable to ensure learners comprehend the characteristics as well as technical capabilities of wikis. This will allow these learners to use wikis to their full potential in the writing process. Wikis are known to provide communication, file sharing and sense-making affordances (Kuswara \& Richards, 2011). The study by Kuswara and Richards (2011) indicates the lack of ability among students to perceive the affordance of the tool in facilitating collaborative activity meaningfully. They found that students mainly used wikis for communicating and sharing of resources among peers rather than for creating new information or knowledge in the interaction (sense-making). Thus, to produce effective collaboration, instructors are expected to provide specific guidance on the conceptions of collaboration which is not merely for information sharing and task coordination but more importantly, making sense out of it by explaining explicitly how the technical features afforded such activities.

Cole (2009) points out the need to obtain a balance between the time needed to learn utilizing a technological tool and perceived benefits of using it. Some forms of preparation such as learner training (Lai \& Morrison, 2013) to introduce students to the different ways in which wikis can be used in language learning can facilitate them become proficient with the tool in a shorter period and subsequently use wikis to the full potential during collaborative writing processes. Hubbard (2013) found evidence from his review of existing studies that i) it is inappropriate to assume digital natives possess the learning competency needed for technology-enhanced language learning; ii) insufficient learner training explained ineffective learning experience, and iii) learner training improved learning outcomes.

The study by Cole (2009) also suggests that students' perceived usefulness of wikis is positively correlated to assessment structures. Therefore, besides providing learner training, instructors should also ensure the assessment of collaborative wiki writing to be extended beyond the final writing product. The assessment should also focus on the collaborative writing process which includes how students make use of the various wiki affordances to improve their wiki write-up.

Reflection 3: A user-friendly system generally means the absence of technical problems and intuitive interface that allows accurate and fast interaction. Students' perceived ease of use of the wiki tool is also found to affect group collaboration. Thus, this suggests the importance for instructors to choose a wiki platform that provide all necessary technical features to support the wiki task given to students. While most wiki platforms provide common features such as allowing individual and/or group editing of wiki content, some wiki platforms do not provide page history feature, WYSIWYG (What You See Is What You Get) interface, and/or flexibility on the language used on the wiki interface. Thus, it is important for instructors to compare the platforms before choosing the right one for the students to use. The WikiMatrix website (CosmoCode, 2014) provides an interesting and insightful engine that helps instructors or system administrators of educational institutions to decide on the appropriate wiki platform.

\section{Conclusion}

The present study contributes to the growing body of research regarding the use of wikis in language learning. In particular, the findings reveal pertinent relationship between attitudinal factors with group collaboration. Students' motivation has been identified as the most important factor associated with students' collaboration in completing the writing task based on the questionnaire and behavioural data. This is followed by their perceived usefulness and perceived ease of use of wikis. Clearly, for an effective group dynamics to flourish in the wiki environments, 
students must be exposed to the various technical capabilities of the tool. By understanding what wikis can do to assist them in writing, it gives students greater confidence and indirectly increases their motivation to write. The findings from behavioural data also revealed students' willingness to spend more time to collaboratively work on the writing task assigned through the wiki platform. The implications as discussed in the earlier section offer valuable pedagogical considerations for instructors who plan to use wikis in their collaborative learning environments. Future studies may replicate this work for other subject matters to examine the generalizability of these associations as well as to examine whether students' differences in terms of learning styles and learning abilities are also affecting wiki group collaboration.

\section{References}

1. Alm, A. (2006). CALL for autonomy, competence and relatedness: Motivating language learning environments in Web 2.0. In The JALT CALL Journal, 2(3), (pp. 29-38).

2. Ang, C.S.; Zaphiris, P. and Wilson, S. (2005). Wiki-supported Collaborative Narrative Construction in Game Communities. In the Proceedings of The ECSCW'05 workshop on Computer Games CSCW.

3. Aron, A.; Aron, E.N. and Coups, E.J. (2006). Statistics for psychology (4 $4^{\text {th }}$ ed.). Upper Saddle River, N. J.: Pearson Education.

4. Augar, N.; Raitman, R. and Zhou, W. (2004). Teaching and learning online with wikis. In Beyond the comfort zone: proceedings of the $21^{\text {st }}$ ASCILITE Conference, Perth, 5-8 December (pp. 95104). ASCILITE.

5. Baird, D.E. and Fisher, M. (2005). Neomillennial user experience design strategies: Utilizing social networking media to support "always on" learning styles. In Journal of educational technology systems, 34(1), (pp. 5-32).

6. Bower, M. (2007). Independent, synchronous and asynchronous an analysis of approaches to online concept formation. In ACM SIGCSE Bulletin, (Vol. 39, No. 3, pp. 141-145). ACM.

7. Bower, M.; Woo, K.; Roberts, M. and Watters, P. (2006, July). Wiki pedagogy-A tale of two wikis. In the Proceedings of the $7^{\text {th }}$ International Conference on Information Technology Based Higher Education and Training (ITHET 06), Sydney, Australia.

8. Brandl, K. (2005). Are you ready to "Moodle"? In Language Learning \& Technology, 9(2), (pp. 16-23).

9. Brophy, J.E. (2013). Motivating students to learn. Routledge.

10. Buffa, M. and Gandon, F. (2006). SweetWiki: semantic web enabled technologies in Wiki. In the Proceedings of the 2006 international symposium on Wikis, (pp. 69-78). ACM.

11. Chao, Y.C.J. and Lo, H.C. (2011). Students' perceptions of wiki-based collaborative writing for learners of English as a foreign language. In Interactive Learning Environments, 19(4), (pp. 395-411).

12. Choy, S.O. and Ng, K.C. (2007). Implementing wiki software for supplementing online learning. In Australasian Journal of Educational Technology, 23(2), (pp. 209-226). http:/ /www.ascilite.org.au/ajet/ajet23/choy.html

13. Cole, M. (2009). Using Wiki technology to support student engagement: Lessons from the trenches. In Computers \& Education, 52(1), (pp. 141-146).

14. CosmoCode (2014). WikiMatrix: Compare them all. Retrieved March 27, 2014 from http://www.wikimatrix.org 
15. Davis, F.D. (1989). Perceived usefulness, perceived ease of use and user acceptance of information technology. In MIS Quarterly, 13(3), (pp. 319-40).

16. Denoyer, L. and Gallinari, P. (2007). The wikipedia xml corpus. In Comparative Evaluation of XML Information Retrieval Systems, (pp. 12-19). Springer Berlin Heidelberg.

17. de Paiva Franco, C. (2008). Using wiki-based peer-correction to develop writing skills of Brazilian EFL learners. In Novitas-Royal, 2(1), (pp. 49-59).

18. Engstrom, M.E. and Jewett, D. (2005). Collaborative learning the wiki way. In TechTrends, 49(6), (pp. 12-15).

19. Greener, S. (2009). Talking online: reflecting on online communication tools. In Campus-Wide Information Systems, 26(3), (pp. 178-190).

20. Healey, D.; Hanson-Smith, E.; Hubbard, P.; Ioannou-Georgious, S.; Kessler, G. and Ware, P. (2011). TESOL technology standards: Description, implementation, integration. Alexandria, VA: TESOL.

21. Holec, H. (2009). Autonomy in language learning: A single pedagogical paradigm or two? In F. Kjisik, P. Voller, N. Aoki \& Y. Nakata (eds.), Mapping the terrain of learner autonomy: Learning environments, learning communities and identities, (pp. 21-47). Tampere, Finland: Tampere University Press.

22. Hsu, Y.C.; Ching, Y.H. and Grabowski, B.L. (2014). Web 2.0 applications and practices for learning through collaboration. In Handbook of research on educational communications and technology, (pp. 747-758). Springer.

23. Hubbard, P. (2013). Making a Case for Learner Training in Technology Enhanced Language Learning Environments. In CALICO Journal, 30(2).

24. Hughes, J.E. and Narayan, R. (2009). Collaboration and learning with wikis in post-secondary classrooms. In Journal of Interactive Online Learning, 8(1), (pp. 63-82).

25. Hutchins, E. (2000). Distributed cognition. In N.J. Smelser \& P.B. Baltes (eds.), International Encyclopedia of the Social \& Behavioral Sciences, (pp. 2068-2072). New York.

26. Kawahata, C. and Chung, C.J. (2013). Increasing Student Motivation and Engagement in the Peer Editing Process through the Use of Wiki Technology. In R. McBride \& M. Searson (eds.), Proceedings of Society for Information Technology \& Teacher Education International Conference 2013, (pp. 4492-4496). Chesapeake, VA: AACE.

27. Kessler, G. (2009). Student-initiated attention to form in wiki-based collaborative writing. In Language Learning \& Technology, 13(1), (pp. 79-95).

28. Kessler, G.; Bikowski, D. and Boggs, J. (2012). Collaborative writing among second language learners in academic web-based projects. In Language Learning \& Technology, 16(1), (pp. 91 109).

29. Kuswara, A. and Richards, D. (2011). Matching the affordances of wikis to collaborative learning: A case study of it project students. In the Proceedings of the $44^{\text {th }}$ Hawaii International Conference on System Sciences.

30. Lai, C. and Morrison, B. (2013).Towards an agenda for learner preparation in technology enhanced language learning environments. In CALICO Journal, 30(2), (pp. 154-162).

31. Laru, J.; Näykki, P. and Järvelä, S. (2012). Supporting small-group learning using multiple Web 2.0 tools: A case study in the higher education context. In The Internet and Higher Education, 15(1), (pp. 29-38). 
32. Lee, L. (2010). Exploring wiki-mediated collaborative writing: A case study in an elementary Spanish course. In Calico Journal, 27(2), (pp. 260-272).

33. Legris, P.; Ingham, J. and Collerette, P. (2003). Why do people use information technology? A critical review of the technology acceptance model. In Information \& management, 40(3), (pp. 191-204).

34. Levy, M. (2009). Technologies in use for second language learning. In Modern Language Journal, 93, (pp. 769-782).

35. Li, M. (2012). Use of wikis in second/foreign language classes: A literature review. In CALLEJ, 13(1), (pp. 17-35).

36. Li, X.; Chu, S.K.W.; Ki, W.W. and Woo, M. (2010). Students and teacher's attitudes and perceptions toward collaborative writing with Wiki in a primary four Chinese classroom. In Proceedings of the $3^{\text {rd }}$ Edition of the ICT for Language Learning Conference.

37. Li, X.; Chu, K.; Ki, W.W. and Woo, M.M. (2012). Using a wiki-based collaborative process writing pedagogy to facilitate collaborative writing among Chinese primary school students. In Australasian Journal of Educational Technology, 28(1), (pp. 159-181).

38. Lund, A. (2008). Wikis: A collective approach to language production. In ReCALL, 20(1), (pp. 35-54).

39. Lund, A. and Smørdal, O. (2006). Is there a space for the teacher in a WIKI? In Proceedings of the 2006 international symposium on Wikis, (pp. 37-46). ACM.

40. Ma, W.W. and Yuen, A.H. (2008). News writing using wiki: impacts on learning experience of student journalists. In Educational Media International, 45(4), (pp. 295-309).

41. Mak, B. and Coniam, D. (2008). Using wikis to enhance and develop writing skills among secondary school students in Hong Kong. In System, 36(3), (pp. 437-455).

42. Neumann, D.L. and Hood, M. (2009). The effects of using a wiki on student engagement and learning of report writing skills in a university statistics course. In Australasian Journal of Educational Technology, 25(3), (pp. 382-398).

43. Nicol, D.; Littlejohn, A. and Grierson, H. (2005). The importance of structuring information and resources within shared workspaces during collaborative design learning. In Open Learning: The Journal of Open and Distance Learning, 20(1), (pp. 31-49).

44. Parker, K. and Chao, J. (2007). Wiki as a teaching tool. In Interdisciplinary Journal of e-learning and Learning Objects, 3(1), (pp. 57-72).

45. Raitman, R.; Augar, N. and Zhou, W. (2005, July). Employing wikis for online collaboration in the e-learning environment: Case study. In Information Technology and Applications, 2005. ICITA 2005. Third International Conference on (Vol. 2, pp. 142-146). IEEE.

46. Ravid, G.; Kalman, Y.M. and Rafaeli, S. (2008). Wikibooks in higher education: Empowerment through online distributed collaboration. In Computers in Human Behavior, 24(5), (pp. 1913-1928).

47. Schaffert, S. (2006). IkeWiki: A semantic wiki for collaborative knowledge management. In the Proceedings of Enabling Technologies: Infrastructure for Collaborative Enterprises, 2006, (pp. 388396). WETICE'06. $15^{\text {th }}$ IEEE International Workshops. IEEE.

48. Schwartz, L.; Clark, S.; Cossarin, M. and Rudolph, J. (2004). Educational wikis: Features and selection criteria. In The International Review of Research in Open and Distance Learning, 5(1). http://www.irrodl.org/index.php/irrodl/article/view/163/244 
49. Sotillo, S. (2002). Constructivist and collaborative learning in a wireless environment. In TESOL Journal, 11(3), (pp. 16-20).

50. Storch, N. (2005). Collaborative writing: Product, process, and students' reflections. In Journal of Second Language Writing, 14(3), (pp. 153-173).

51. Su, F. and Beaumont, C. (2010). Evaluating the use of a wiki for collaborative learning. In Innovations in Education and Teaching International, 47(4), (pp. 417-431).

52. Sun, Z. and Qiu, X. (2014). Evaluating the use of wikis for EFL: a case study of an undergraduate English writing course in China. In International Journal of Information Technology and Management, 13(1), (pp. 3-14).

53. Thorne, S.L. and Payne, J.S. (2005). Evolutionary trajectories, Internet-mediated expression, and language education. In Calico Journal, 22(3), (pp. 371-397).

54. Vygotsky, L.S. (1978). Mind in society: The development of higher psychological processes. Cambridge, MA: Harvard University Press.

55. Wang, Y.C. (2014a). Promoting collaborative writing through wikis: a new approach for advancing innovative and active learning in an ESP context. In Computer Assisted Language Learning, (published online), (pp. 1-14).

56. Wang, Y.C. (2014b). Using wikis to facilitate interaction and collaboration among EFL learners: A social constructivist approach to language teaching. In System, 42, (pp. 383-390).

57. Wang, H.C.; Lu, C.H.; Yang, J.Y.; Hu, H.W.; Chiou, G.F.; Chiang, Y.T. and Hsu, W.L. (2005). An empirical exploration of using wiki in an English as a second language course. In Advanced Learning Technologies, 2005, (pp. 155-157). ICALT 2005. Fifth IEEE International Conference. IEEE.

58. Wang, C.M. and Turner, D. (2004). Extending the wiki paradigm for use in the classroom. In the Proceedings of Information Technology: Coding and Computing, 2004, (Vol.1, pp. 255-259). IEEE.

59. Weiss, S.; Urso, P. and Molli, P. (2007). Wooki: a p2p wiki-based collaborative writing tool. In Web Information Systems Engineering-WISE 2007, (pp. 503-512). Springer Berlin Heidelberg.

60. Wheeler, S.; Yeomans, P. and Wheeler, D. (2008). The good, the bad and the wiki: Evaluating student-generated content for collaborative learning. In British journal of educational technology, 39(6), (pp. 987-995).

61. Woo, M.K.; Chu, S.K.W. and Li, X. (2013). Peer-feedback and revision process in a wiki mediated collaborative writing. In Educational Technology Research and Development, 61(2), (pp. 279-309).

62. Zenotz, V. (2012). Awareness development for online reading. In Language Awareness, 21, (pp. 85-100).

63. Zorko, V. (2009). Factors affecting the way students collaborate in a wiki for English language learning. In Australasian Journal of Educational Technology, 25(5), (pp. 645-66).

\section{Acknowledgements}

The authors acknowledge the financial and facilities support rendered by the authors' university to accomplish this project. 